\title{
Prospective evaluation of the impact of stress, anxiety, and depression on household income among young women with early breast cancer from the Young and Strong trial
}

Erin E. Cook ${ }^{1,2}$, Shoshana M. Rosenberg ${ }^{3,4}$, Kathryn J. Ruddy ${ }^{5}$, William T. Barry ${ }^{6}$, Mary Greaney ${ }^{7}$, Jennifer Ligibel ${ }^{3,4}$, Kim Sprunck-Harrild ${ }^{3}$, Michelle D. Holmes ${ }^{1}$, Rulla M. Tamimi ${ }^{1}$, Karen M. Emmons ${ }^{1}$ and Ann H. Partridge ${ }^{3,4^{*}}$ (D)

\begin{abstract}
Background: Young women with breast cancer tend to report lower quality of life and higher levels of stress than older women with breast cancer, and this may have implications for other psychosocial factors including finances. We sought to determine if stress, anxiety, and depression at diagnosis were associated with changes in household income over 12-months in young women with breast cancer in the United States.

Methods: This study was a prospective, longitudinal cohort study comprised of women enrolled in the Young and Strong trial. Of the 467 women aged 18-45 newly diagnosed with early-stage breast cancer enrolled in the Young and Strong trial from 2012 to 2013, 356 (76\%) answered income questions. Change in household income from baseline to 12 months was assessed and women were categorized as having lost, gained, maintained the same household income $<\$ 100,000$, or maintained household income $\geq \$ 100,000$. Patient-reported stress, anxiety, and depression were assessed close to diagnosis at trial enrollment. Adjusted multinomial logistic regression models were used to compare women who lost, gained, or maintained household income $\geq \$ 100,000$ to women who maintained the same household income $<\$ 100,000$.

* Correspondence: Ann_Partridge@dfci.harvard.edu

${ }^{3}$ Medical Oncology, Dana-Farber Cancer Institute, 450 Brookline Avenue,

Boston, MA 02215, USA

${ }^{4}$ Harvard Medical School, Boston, MA, USA

Full list of author information is available at the end of the article

C C The Author(s). 2020 Open Access This article is licensed under a Creative Commons Attribution 4.0 International License, which permits use, sharing, adaptation, distribution and reproduction in any medium or format, as long as you give appropriate credit to the original author(s) and the source, provide a link to the Creative Commons licence, and indicate if changes were made. The images or other third party material in this article are included in the article's Creative Commons licence, unless indicated otherwise in a credit line to the material. If material is not included in the article's Creative Commons licence and your intended use is not permitted by statutory regulation or exceeds the permitted use, you will need to obtain permission directly from the copyright holder. To view a copy of this licence, visit http://creativecommons.org/licenses/by/4.0/ The Creative Commons Public Domain Dedication waiver (http://creativecommons.org/publicdomain/zero/1.0/) applies to the data made available in this article, unless otherwise stated in a credit line to the data. 
(Continued from previous page)

Results: Although most women maintained household income $\mathbf{2} \$ 100,000$ (37.1\%) or the same household income $<\$ 100,000$ (32.3\%), 15.4\% lost household income and 15.2\% gained household income. Stress, anxiety, and depression were not associated with gaining or losing household income compared to women maintaining household incomes $<\$ 100,000$. Women with household incomes $<\$ 50,000$ had a higher risk of losing household income compared to women with household incomes $\geq \$ 50,000$. Women who maintained household incomes $\geq \$ 100,000$ were less likely to report financial or insurance problems. Among women who lost household income, 56\% reported financial problems and 20\% reported insurance problems at 12 months.

Conclusions: Baseline stress, anxiety, and depression were not associated with household income changes for young women with breast cancer. However, lower baseline household income was associated with losing household income. Some young survivors encounter financial and insurance problems in the first year after diagnosis, and further support for these women should be considered.

Trial registration: Clinicaltrials.gov, NCT01647607; date registered: July 23, 2012.

Keywords: Breast cancer, Young adult, Income, Anxiety, Stress, Depression

\section{Introduction}

While only $7 \%$ of breast cancer cases were diagnosed among women under age 40 in the United States in 2017, breast cancer is the most common cancer among adolescent and young adult women ages 15-39 in the United States [1, 2]. Breast cancer is often more aggressive in young women than older women; however, the relative 5year survival for women ages 35-39 is still high at nearly $90 \%[2,3]$. Nevertheless, young women with breast cancer tend to report lower quality of life (QOL) and higher levels of stress than older women with breast cancer both at diagnosis and in longer term follow-up [4-7]. This increased distress may impair subsequent psychosocial outcomes including employment, and the burden of employment and financial disturbances after treatment in younger cancer survivors may further impact their subsequent QOL outcomes [4, 5, 7-9]. These financial and employment disturbances can impact both the woman with cancer and her family members [10].

Employment opportunities and financial stability are of particular concern for this younger cohort of women with breast cancer since most women are in the start or prime of their careers and have young families at the time of diagnosis. Financial and social support for cancer patients vary from country to country based on the policies and socio-cultural norms of each country. Additionally, economic conditions and current policy can change. For example, the economic recession in 2008 and the introduction of the Affordable Care Act in 2010 had large impacts on cancer patients' financial situations. Additionally in the United States, some laws impact patients with cancer, such as the Family and Medical Leave Act (FMLA) which requires employers to allow unpaid leave for certain employees and the Americans With Disabilities Act (ADA) [11] which requires employers to make reasonable accommodations for employees with cancer. However, disruption to employment during this time can be challenging due to employment's link to financial stability and health insurance, as well as the added stress and anxiety that comes from managing taking time off from work during cancer treatment [12]. Previous research has noted that cancer patients face financial challenges from their care, such as loss of income due to work absences, that can result in reducing spending on other necessities such as food or other bills $[13,14]$. These financial burdens, understandably, can result in additional stress and worry for cancer patients [15-17].

However, the impact of stress, anxiety and depression at diagnosis on changes to employment and income levels has not been examined in as much detail in cancer patients. In other populations, some research has explored the association between stress, anxiety and depression with changes in employment. For example, post-traumatic stress disorder and depression have been associated with lower employment $[18,19]$. Additionally, a systematic literature review on return to work among breast cancer survivors found that depression and emotional distress were barriers of returning to work [20]. Since a cancer diagnosis is a stressful event that can results in higher levels of stress, depression and/or anxiety, it is of interest to understand if they have any impact on income [21-23]. This study aimed to determine if stress, anxiety, or depression is associated with household income changes for young women with breast cancer over the first 12 months after diagnosis. Household income was used based its association with well-being of individuals and populations as well as its availability and common use by economists [24-26].

\section{Methods}

\section{Study population}

The randomized trial, Young and Strong: An Education and Supportive Care Intervention Study for Young 
Women with Breast Cancer (NCT01647607), which was led by the Dana- Farber Cancer Institute, provided data for this study [27, 28]. This trial enrolled 467 Englishspeaking women ages 18-45 with newly diagnosed stage I-III breast cancer. Enrollment occurred from July 2012 to December 2013 at 14 academic and 40 community practices around the United States. Practices were randomized to the Young Women's Intervention (YWI) or the Physical Activity Intervention (PAI). The YWI contained information about fertility, genetic testing, physical activity, and survivorship. The PAI contained information about physical activity. Participants completed surveys at baseline, 3, 6, and 12 months. Baseline assessment often occurred at the first medical oncology visit for the participants. Details on the trial can be found in previous publications $[27,28]$.

Since the YWI discussed how breast cancer impacts employment, we examined if the intervention arm impacted change in income and found no statistically significant associations (eTable 1). Thus, we combined the YWI and PAI arms for the rest of this analysis. This study was a prospective, longitudinal cohort study of women who participated in the Young and Strong trial. Women who did not respond to the 12-month survey $(N=51)$, had stage IV disease $(N=2)$, and did not report household income on the baseline and 12-month surveys $(N=58)$ were excluded, leaving an analytic sample of 356 women. Women excluded for missing income information tended to be older and less educated than women included (eTable 2).

\section{Exposures}

The main exposures were baseline measures of stress, anxiety, and depression. Stress was measured using the Perceived Stress Scale (PSS) with categories of low (< $14)$, moderate (14-26), or high ( $\geq 27)$ stress [29]. Anxiety was measured from the Hospital Anxiety and Depression Scale (HADS) anxiety subscale with categories of normal $(<8)$, borderline anxious $(8-10)$, or anxious $(\geq$ 11) $[30,31]$. Depression was measured by the Center for Epidemiological Studies Depression Scale (CES-D) and was a binary variable of no depression $(<16)$ or depression $(\geq 16)$ [32]. We used the CES-D over the HADS depression subscale due to its better ability to detect major depression [33].

\section{Outcomes}

The primary outcome was change in household income between the baseline and 12-month survey. Household income refers to the combined income of all people living together in a household. Women self-reported their household income from all sources before taxes in a categorical variable $(<\$ 5000, \$ 5000-\$ 11,999, \$ 12,000-\$ 15$, 999, $\$ 16,000-\$ 24,999, \$ 25,000-\$ 34,999, \$ 35,000-\$ 49$,
999, $\$ 50,000-\$ 74,999, \quad \$ 75,000-\$ 99,999, \quad$ and $\geq \$ 100$, $000)$. We created a categorical variable for change in household income: losing, gaining, maintaining $\geq \$ 100$, 000 , or maintaining same household income $<\$ 100,000$. We were unable to determine how household incomes changed if women maintained household incomes $\geq$ $\$ 100,000$ based on the categories of the household income question (ex: $\$ 150,000$ to $\$ 200,000$ or vice versa). Therefore, we separated women who reported the same household income category at baseline and 12-months into maintaining the same household income $<\$ 100,000$ and maintaining household income $\geq \$ 100,000$. We were also unable to determine how household incomes changed if women maintained household incomes $<\$ 5000$; however, since this total was so low and the category was relatively small we did not separate out these women. Women were categorized as losing or gaining household income, regardless of their household income category, if they reported a different household income category at baseline and 12-months.

Women reported financial, insurance, and working concerns on the 3- and 12-month surveys using a modified CAncer Rehabilitation Evaluation System. Short Form (CARES-SF) questionnaire [34]. For all women we examined employment status and responses to the questions "I have financial problems" and "I have insurance problems." Employed women were asked: "I have difficulty talking to people who work with me about the cancer," "I have difficulty asking for time off work for medical treatments," and "I am worried about being fired." Unemployed women were asked if they looked for work in the past month. Responses to these questions were categorized as no if respondents reported "not at all" or "a little" and yes if respondents reported "a fair amount," "much," or "very much."

\section{Statistical analysis}

Descriptive statistics, including the number, percentage, and chi-square or Fisher's exact test (when $\leq 5$ women), were calculated by change in income for demographic, cancer, psychosocial, employment, and financial information. Separate multinomial logistic regression models, with the reference category being same household income $<\$ 100,000$, analyzed how stress, anxiety, and depression were associated with changes in household income. Models were adjusted for age (continuous), race/ethnicity (Hispanic, Black, other vs. White), marital status (yes vs. no), children (yes vs. no), stage, and baseline household income $(\geq \$ 50,000$ vs. $<\$ 50,000)$. We performed multiple sensitivity analyses. First, we did not have employment information at baseline, so we added 3-month employment status as a proxy. Second, we created propensity scores and included them as quintiles in the regression models. Lastly, since the survey household 
income categories were not uniform ranges $(\$ 5000-\$ 25$, 000), we grouped women into even income categories at baseline and 12 months $(<\$ 25,000, \$ 25,000-\$ 49,999$, $\$ 50,000-\$ 74,999, \quad \$ 75,000-\$ 99,999, \quad$ and $\geq \$ 100,000$ ). From these categories we looked at women who lost, gained, maintained the same income $<\$ 100,000$, and maintained incomes $\geq \$ 100,000$.

Results were considered statistically significant if $p<$ 0.05 . SAS 9.4 was used for the cluster randomized analyses and StataIC 14 was used for the remaining analyses $[35,36]$. The study was approved by the Dana-Farber Cancer Institute Institutional Review Board, which oversaw most of the study sites; however, some sites maintained their own institutional review. Written informed consent was obtained from all participants prior to study enrollment.

\section{Results}

Over 12 months, 37\% of women maintained household incomes $\geq \$ 100,000$, 32\% maintained the same household income $<\$ 100,000,15 \%$ gained household income, and $15 \%$ lost household income (Table 1). Women in the income change categories were similar to each other in terms of demographic, cancer characteristics, and psychosocial measures. However, women maintaining incomes $\geq \$ 100,000$ were more likely than women in the other household income categories to be more educated, married, and have stage I disease. They were less likely to have chemotherapy and depression. The proportion of women experiencing high stress ranged from 3.1\% (women maintaining $\geq \$ 100,000$ ) to $13.2 \%$ (women losing income). Anxiety ranged from $30.7 \%$ of women with the same income $<\$ 100,000$ to $42.4 \%$ of women gaining income. Depression ranged from $31.5 \%$ of women maintaining $\geq \$ 100,000$ to $54.0 \%$ of women losing income. Among women who lost or gained household income, the estimated dollar amount of change in household income was similar (eTable 3).

Psychosocial measures, including stress, anxiety and depression, were not associated with losing, gaining, or maintaining household incomes $\geq \$ 100,000$ compared to maintaining the same household income $<\$ 100,000$ (Table 2). Specifically, losing household income was not associated with high stress (Risk ratio, $\mathrm{RR}=2.42$, 95\% confidence internal $[\mathrm{CI}] 0.72-8.08)$, anxiety $(\mathrm{RR}=1.12$, 95\% CI $0.50-2.50$ ), or depression ( $\mathrm{RR}=1.41,95 \% \mathrm{CI}$ $0.70-2.85)$ at baseline. Women reporting baseline household income $<\$ 50,000$ were 2.23 times higher risk of losing income compared to those reporting household incomes $\geq \$ 50,000$ (95\% CI 1.04-4.78). Women with stage III disease had a 2.68 times higher risk of losing income than stage I disease with borderline statistical significance (95\% CI 0.98-7.37). Women with baseline household incomes $<\$ 50,000$ compared to $\geq \$ 50,000$ were more likely to gain income $(\mathrm{RR}=8.47,95 \% \mathrm{CI}$ $3.87-18.81$ ). Married women were more likely to gain or maintain household income $\geq \$ 100,000$ than unmarried women $(\mathrm{RR}=3.76,95 \% \mathrm{CI} 1.50-9.41 ; \mathrm{RR}=2.56,95 \% \mathrm{CI}$ 1.08-6.06; respectively). Similar results were seen when the models were adjusted using propensity score quintiles (eTable 4), adjusted for 3-month employment, and when we used the change in household income variable from the uniform income categories (data not shown).

Women maintaining incomes $\geq \$ 100,000$ reported financial and insurance problems less frequently than women in the other household income change categories (Table 3). Of women maintaining incomes $\geq \$ 100,000$, $5.3 \%$ at 3 months and $7.6 \%$ at 12 months reported financial problems, compared to $49.1 \%$ at 3 months and $56.4 \%$ at 12 months of women losing income (3 and 12month $p<0.0001)$. Women maintaining incomes $\geq$ $\$ 100,000$ (3 month $=3.0 \%, 12$ month $=5.3 \%$ ) and women maintaining the same income $<\$ 100,000$ (3 month $=$ $7.8 \%, 12$ month $=7.0 \%$ ) reported insurance problems less frequently than women who gained ( 3 month $=22.2 \%$, 12 month $=11.1 \%)$ or lost income ( 3 month $=25.5 \%, 12$ month $=20.0 \%) \quad(3$ month: $p<0.0001,12$ month: $p=$ $0.02)$. Overall, approximately $60 \%$ of women were working at 3 months and $79 \%$ were working at 12 months.

The proportion of employed women was similar among household income change categories (Table 3). Two women lost employment between the 3 and 12month surveys, while 53 gained employment, 210 remained employed, and 66 remained unemployed (Table 1). Among employed women, worries about discussing cancer with coworkers or taking time off work were similar across household income change categories. At 3 months, the percentage worried about being fired was highest among women with the same income $<\$ 100,000$ (13.6\%) and women losing income (18.2\%). At 12 months, the percentage worried about being fired varied by income change ( $0 \%$ gaining income to $21 \%$ losing income, $p=0.001)$. A small proportion of unemployed women reported looking for work in the past month.

\section{Discussion}

In this study of young women with breast cancer, stress, anxiety and depression following diagnosis were not associated with changes in household income over the subsequent year. However, our finding that lower household income was associated with losing household income suggests that these lower income women may be more vulnerable to income loss, and clinicians caring for these women may want to proactively offer available resources to address financial needs.

Most QOL literature examines how the financial burden of cancer influences QOL, rather than looking at 
Table 1 Participant characteristics at baseline survey by change in household income for women in the Young and Strong trial in 2012-2013

\begin{tabular}{|c|c|c|c|c|c|}
\hline & \multicolumn{5}{|c|}{ Change in Household Income } \\
\hline & $\begin{array}{l}\text { Maintain } \geq \$ 100,000 \\
(N=132)\end{array}$ & $\begin{array}{l}\text { Same }<\$ 100,000 \\
(N=115)\end{array}$ & Gained $(N=54)$ & Lost $(N=55)$ & \\
\hline & N. (\%) & N. (\%) & N. (\%) & N. (\%) & $p$ value \\
\hline \multicolumn{6}{|l|}{ Demographics } \\
\hline Age & & & & & 0.16 \\
\hline$<35$ & $18(13.6)$ & $30(26.1)$ & $13(24.1)$ & $15(27.3)$ & \\
\hline $35-39$ & $38(28.8)$ & $23(20.0)$ & $15(27.8)$ & $11(20.0)$ & \\
\hline $40-45$ & $76(57.6)$ & $62(53.9)$ & $26(48.2)$ & $29(52.7)$ & \\
\hline Education & & & & & $<0.0001^{\mathrm{a}}$ \\
\hline$\leq$ High School & $1(0.8)$ & $13(11.3)$ & $11(20.4)$ & $10(18.2)$ & \\
\hline$\geq$ Some College & $131(99.2)$ & $102(88.7)$ & $43(79.6)$ & $45(81.8)$ & \\
\hline Married & & & & & $<0.0001$ \\
\hline Yes & $122(92.4)$ & $82(71.3)$ & $43(79.6)$ & $41(74.6)$ & \\
\hline No & $10(7.6)$ & $33(28.7)$ & $11(20.4)$ & $14(25.5)$ & \\
\hline Children & & & & & 0.07 \\
\hline Yes & $107(81.1)$ & $78(67.8)$ & $36(67.7)$ & $40(74.1)$ & \\
\hline No & $25(18.9)$ & $37(32.2)$ & $18(33.3)$ & $14(25.9)$ & \\
\hline Race/Ethnicity & & & & & 0.31 \\
\hline Non-Hispanic, White & $108(81.8)$ & $85(74.6)$ & $38(70.4)$ & $41(74.6)$ & \\
\hline Hispanic, Black, Other & $24(18.2)$ & $29(25.4)$ & $16(29.6)$ & $14(25.5)$ & \\
\hline Region & & & & & 0.19 \\
\hline Northeast & $38(28.8)$ & $30(26.1)$ & $11(20.4)$ & $12(21.8)$ & \\
\hline South/Southeast & $22(16.7)$ & $34(29.6)$ & 18 (33.3) & $18(32.7)$ & \\
\hline Midwest & $46(34.9)$ & $38(33.0)$ & $15(27.8)$ & $18(32.7)$ & \\
\hline West & $26(19.7)$ & $13(11.3)$ & $10(18.5)$ & $7(12.7)$ & \\
\hline Change in Employment & & & & & $0.23^{\mathrm{a}}$ \\
\hline None-Employed & $85(68.0)$ & $66(62.3)$ & $26(54.2)$ & $33(63.5)$ & \\
\hline None-Unemployed & $20(16.0)$ & $20(18.9)$ & $11(22.9)$ & $15(28.9)$ & \\
\hline Lost & $1(0.8)$ & $0(0.0)$ & $1(2.1)$ & $0(0.0)$ & \\
\hline Gained & $19(15.2)$ & $20(18.9)$ & $10(20.8)$ & $4(7.7)$ & \\
\hline Household Income & & & & & $<0.0001$ \\
\hline$<\$ 50,000$ & $0(0.0)$ & $32(27.8)$ & $37(68.5)$ & $23(41.8)$ & \\
\hline$\$ 50,000-\$ 99,999$ & $0(0.0)$ & $83(72.2)$ & $17(31.5)$ & $21(38.2)$ & \\
\hline$\geq \$ 100,000$ & $132(100.0)$ & $0(0.0)$ & $0(0.0)$ & $11(20.0)$ & \\
\hline \multicolumn{6}{|l|}{ Cancer } \\
\hline Stage & & & & & 0.01 \\
\hline I & $62(47.0)$ & $39(33.9)$ & $12(22.2)$ & $14(25.5)$ & \\
\hline$\|$ & $54(40.9)$ & $61(53.0)$ & $31(57.4)$ & $28(50.9)$ & \\
\hline III & $16(12.1)$ & $15(13.0)$ & $11(20.4)$ & $13(23.6)$ & \\
\hline Estrogen Receptor & & & & & 0.19 \\
\hline Positive & $107(81.1)$ & $82(71.3)$ & $37(68.5)$ & $40(72.7)$ & \\
\hline Negative & $25(18.9)$ & $33(28.7)$ & $17(31.5)$ & $15(27.3)$ & \\
\hline Progesterone Receptor & & & & & 0.39 \\
\hline Positive & $99(75.0)$ & $79(68.7)$ & $36(66.7)$ & 35 (63.6) & \\
\hline
\end{tabular}


Table 1 Participant characteristics at baseline survey by change in household income for women in the Young and Strong trial in 2012-2013 (Continued)

\begin{tabular}{|c|c|c|c|c|c|}
\hline & Change in Househole & & & & \\
\hline & $\begin{array}{l}\text { Maintain } \geq \$ 100,000 \\
(N=132)\end{array}$ & $\begin{array}{l}\text { Same }<\$ 100,000 \\
(N=115)\end{array}$ & Gained $(N=54)$ & Lost $(N=55)$ & \\
\hline Negative & $33(25.0)$ & $36(31.3)$ & $18(33.3)$ & $20(36.4)$ & \\
\hline HER2 & & & & & 0.91 \\
\hline Positive & $30(23.1)$ & $26(22.8)$ & $12(22.2)$ & $15(27.3)$ & \\
\hline Negative & $100(76.9)$ & $88(77.2)$ & $42(77.8)$ & $40(72.7)$ & \\
\hline Baseline Cancer T & & & & & \\
\hline Chemotherapy & & & & & 0.01 \\
\hline Yes/Planned & $96(73.3)$ & $97(85.8)$ & $48(88.9)$ & $48(88.9)$ & \\
\hline No & $35(26.7)$ & $16(14.2)$ & $6(11.1)$ & $6(11.1)$ & \\
\hline Radiation & & & & & 0.05 \\
\hline Yes/Planned & $69(61.6)$ & $59(64.8)$ & $39(83.0)$ & $31(72.1)$ & \\
\hline No & $43(38.4)$ & $32(35.2)$ & $8(17.0)$ & $12(27.9)$ & \\
\hline Endocrine Therapy & & & & & 0.53 \\
\hline Yes/Planned & $97(78.9)$ & $78(72.2)$ & $34(69.4)$ & $37(74.0)$ & \\
\hline No & $26(21.1)$ & $30(27.8)$ & $15(30.6)$ & $13(26.0)$ & \\
\hline Baseline Psychoso & & & & & \\
\hline Stress & & & & & $0.15^{\mathrm{a}}$ \\
\hline Low & $52(40.3)$ & $42(37.8)$ & $16(30.2)$ & $14(26.4)$ & \\
\hline Moderate & $73(56.6)$ & $61(55.0)$ & $32(60.4)$ & $32(60.4)$ & \\
\hline High & $4(3.1)$ & $8(7.2)$ & $5(9.4)$ & $7(13.2)$ & \\
\hline Anxiety & & & & & 0.73 \\
\hline Normal & $55(42.0)$ & $50(43.9)$ & 19 (35.9) & $20(37.7)$ & \\
\hline Borderline & $31(23.7)$ & $29(25.4)$ & $11(20.8)$ & $16(30.2)$ & \\
\hline Anxiety & $45(34.4)$ & $35(30.7)$ & $23(42.4)$ & $17(32.1)$ & \\
\hline Depression & & & & & 0.03 \\
\hline No & 85 (68.6) & $63(58.3)$ & $27(54.0)$ & $23(46.0)$ & \\
\hline Yes & $39(31.5)$ & $45(41.7)$ & $23(46.6)$ & $27(54.0)$ & \\
\hline
\end{tabular}

$\left({ }^{\mathrm{a}}\right)$ Fisher's exact test; $\mathrm{N}=$ Number; missing: 1 children, 1 race/ethnicity, 25 employment, 3 HER2, 4 chemotherapy, 63 radiation, 26 endocrine therapy, 10 stress, 5 anxiety, 24 depression; $100 \%$ had/planned surgery; $p$-values were calculated using chi-square tests or Fisher's exact tests (when $\leq 5$ women)

the impact that psychosocial factors can have on finances [7, 37, 38]. However, the amount of distress felt at diagnosis may impact how women balance treatment with work obligations, which in turn may affect their personal income. This study found that stress, anxiety, and depression were not associated with losing or gaining household income, suggesting that the presence of these psychosocial factors may not create a burden large enough to impact household income. A review found that psychosocial factors such as depression and distress made it hard for women with breast cancer to return to work [20]. Additionally, a study using the Surveillance, Epidemiology, and End Results (SEER) database found that $27 \%$ of women reported decreasing work hours due to cancer-related health issues [39]. However, in this study only two women lost employment, while 53 women gained employment between 3 and 12 months. Of note, other studies have reported that a higher proportion of women stop working after a breast cancer diagnosis $[5,38]$. The difference in our findings may be due to the lack of baseline employment and student status data. However, we examined medical records for unemployed women and noted few changes in employment after diagnosis. Furthermore, not returning to work may not be directly linked to changes in household income if other people in the household, such as her partner or parent, compensate for any lost income women with cancer may personally experience. Since this study only examined changes in household income, the measure of household income in this study is likely a combination of the woman's income as well as her partner's income as $81 \%$ of the study sample was married. 
Table 2 Adjusted multinomial logistic regression analysis of stress, anxiety and depression's impact on change in household income among young women with breast cancer

\begin{tabular}{|c|c|c|c|c|c|c|}
\hline & \multicolumn{2}{|c|}{ Lost vs. Same $<\$ 100,000$} & \multicolumn{2}{|c|}{ Gained vs. Same $<\$ 100,000$} & \multicolumn{2}{|c|}{ Maintain $\geq \$ 100,000$ vs. Same $<\$ 100,000$} \\
\hline & $\operatorname{RR}(95 \% \mathrm{Cl})$ & $p$ value & $\mathrm{RR}(95 \% \mathrm{Cl})$ & $p$ value & $\operatorname{RR}(95 \% \mathrm{Cl})$ & $p$ value \\
\hline \multicolumn{7}{|l|}{ Stress } \\
\hline Low & Ref. & & Ref. & & Ref. & \\
\hline Moderate & $1.35(0.63-2.91)$ & 0.44 & $0.96(0.43-2.14)$ & 0.91 & $0.97(0.55-1.74)$ & 0.93 \\
\hline High & $2.42(0.72-8.08)$ & 0.15 & $1.47(0.38-5.72)$ & 0.58 & $0.43(0.11-1.65)$ & 0.22 \\
\hline \multicolumn{7}{|l|}{ Anxiety } \\
\hline Normal & Ref. & & Ref. & & Ref. & \\
\hline Borderline & $1.16(0.50-2.67)$ & 0.73 & $0.88(0.34-2.28)$ & 0.80 & $1.05(0.52-2.11)$ & 0.89 \\
\hline Anxiety & $1.12(0.50-2.50)$ & 0.79 & $1.50(0.65-3.47)$ & 0.34 & $1.26(0.66-2.40)$ & 0.48 \\
\hline \multicolumn{7}{|l|}{ Depression } \\
\hline No & Ref. & & Ref. & & Ref. & \\
\hline Yes & $1.41(0.70-2.85)$ & 0.34 & $0.90(0.42-1.93)$ & 0.78 & $0.73(0.41-1.31)$ & 0.29 \\
\hline \multicolumn{7}{|l|}{ Covariates Only } \\
\hline Age & $0.99(0.93-1.05)$ & 0.71 & $1.01(0.94-1.08)$ & 0.86 & $1.04(0.98-1.10)$ & 0.15 \\
\hline \multicolumn{7}{|l|}{ Cancer Stage } \\
\hline I & Ref. & & Ref. & & Ref. & \\
\hline$\|$ & $1.36(0.62-2.98)$ & 0.57 & $1.64(0.70-3.84)$ & 0.26 & $0.64(0.35-1.14)$ & 0.13 \\
\hline III & $2.68(0.98-7.37)$ & 0.06 & $2.72(0.88-8.37)$ & 0.08 & $0.75(0.31-1.83)$ & 0.53 \\
\hline \multicolumn{7}{|l|}{ Married } \\
\hline No & Ref. & & Ref. & & Ref. & \\
\hline Yes & $1.69(0.72-3.92)$ & 0.23 & $3.76(1.50-9.41)$ & 0.005 & $2.56(1.08-6.06)$ & 0.03 \\
\hline \multicolumn{7}{|l|}{ Children } \\
\hline No & Ref. & & Ref. & & Ref. & \\
\hline Yes & $1.21(0.53-2.76)$ & 0.65 & $0.71(0.30-1.65)$ & 0.42 & $1.49(0.76-2.92)$ & 0.25 \\
\hline \multicolumn{7}{|l|}{ Race/Ethnicity } \\
\hline Non-Hispanic, White & Ref. & & Ref. & & Ref. & \\
\hline Hispanic, Black, other & $1.26(0.57-2.76)$ & 0.57 & $1.32(0.59-3.06)$ & 0.49 & $1.10(0.56-2.19)$ & 0.78 \\
\hline \multicolumn{7}{|l|}{ Baseline Income } \\
\hline$\geq \$ 50,000$ & Ref. & & Ref. & & & \\
\hline$<\$ 50,000$ & $2.23(1.04-4.78)$ & 0.04 & $8.47(3.87-18.81)$ & $<0.0001$ & & \\
\hline
\end{tabular}

Separate models were run for stress, anxiety, depression and covariates only; models were adjusted for age, marriage, children, stage, race/ethnicity, and baseline income; $\mathrm{Cl}$ Confidence interval; $R R$ Risk ratio

In our study, $15 \%$ of women reported losing household income; however, not many women appeared to lose their job and baseline stress, anxiety and depression were not associated with loss of household income. Without large amounts of unemployment for women with breast cancer, lost household income may have been the result of reduced hours for employed women; however, data on hours worked was not collected. Additionally, we do not know if women who remained employed did so because they enjoyed their job or if they felt locked into their job and were afraid to change positions due to worries about insurance or finances. The loss of household income could also be related to income loss for her partner or other member of the household. Partners of women with breast cancer also face psychosocial and economic distress [40-42]. One prior study found that $32 \%$ of partners reduced working hours to help a partner though treatment and 32\% reported a worse financial status [10]. Another found that $5 \%$ of caregivers had to quit their job [43]. While our study did not specifically look at the partner or other members of the household, and there was no way to disaggregate the measure of household income, it's possible that part of the financial loss seen among some participants may have resulted from the impact on the partners' ability to work. However, this study found that 
Table 3 Measures of work, financial, and insurance worries by change in household income among young women with breast cancer in the Young and Strong trial from 2012 to 2013

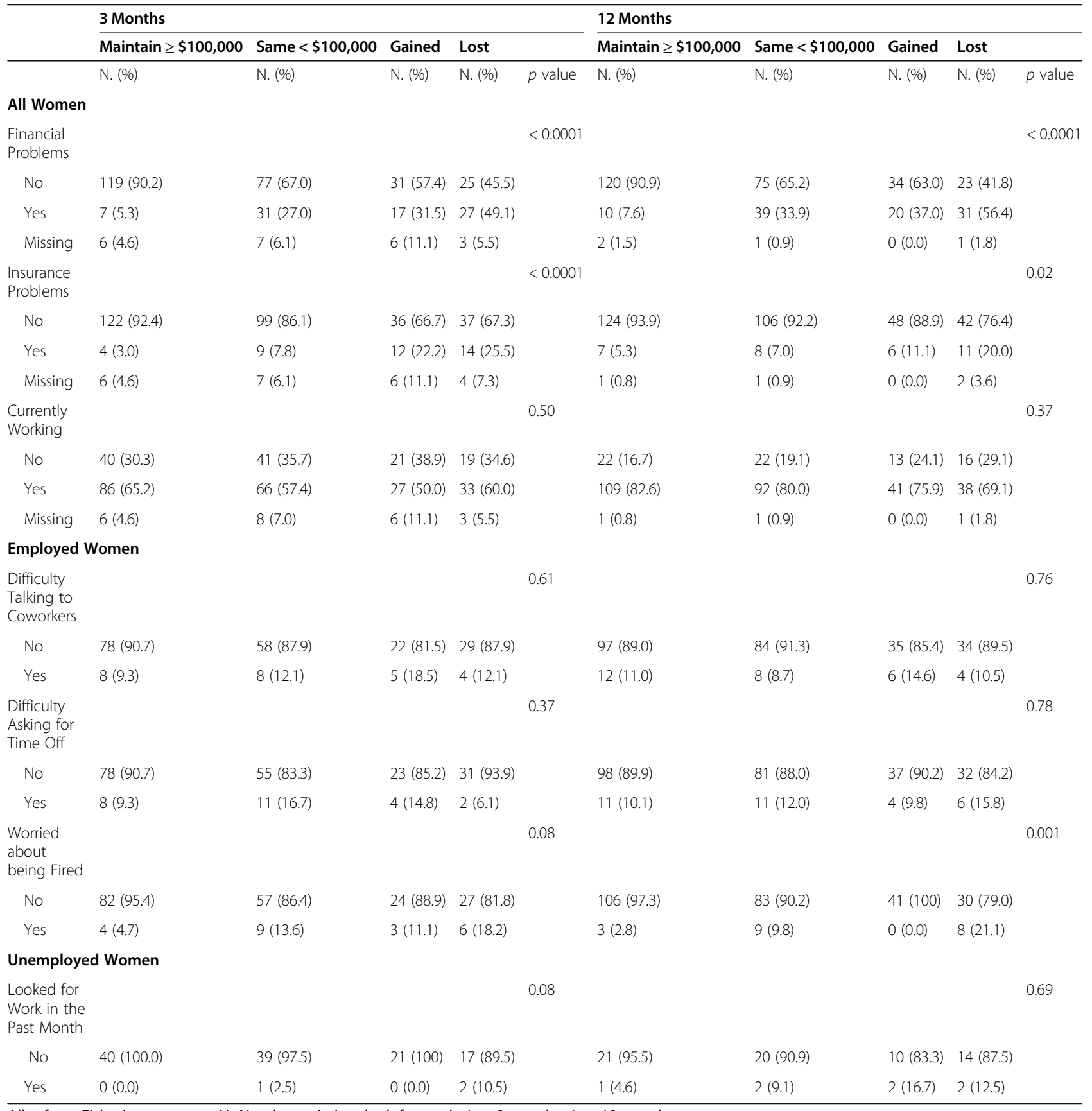

All $p$ from Fisher's exact tests; $\mathrm{N}=$ Number; missing: look for work: 1 at 3 months, 1 at 12 months

married women were more likely to gain income, so the impact of the partner's income is hard to disentangle from the patient's income in this study. Further research examining the impact of cancer diagnosis and treatment on the patient as well as the partner/household could help elucidate this relationship.

While stress, anxiety and depression were not associated with changes in household income, this study found that losing household income was associated with lower baseline household incomes and possibly more advanced disease. Similar findings were found in a SEER study where women with incomes $<\$ 50,000$ had 1.77 times higher odds of a worsening financial status due to breast cancer than women with incomes $\geq \$ 50,000$ [39]. Women with high household incomes may have more resources available that lessen the risk of losing household income and may ease the financial toxicity associated with cancer treatment. In our study, women who 
maintained incomes $\geq \$ 100,000$ were less likely to report financial problems after 12 months than women in the other income categories ( $8 \%$ vs $34 \%$ that maintained income $<\$ 100,00,37 \%$ that gained income and $56 \%$ that lost income). Additionally, women with later stage disease, regardless of income, may find treatments particularly disruptive which may result in reduced work hours. However, similar to our results, the SEER study found that stage III vs. stage I disease was borderline associated with worsening financial statuses (odds ratio $=1.92, p=0.06$ ) [39].

We also found that women with lower incomes were more likely to gain income. Some women with lower incomes and/or their partners may have been students and their income may have increased upon graduation in this young population. Lower income women may have gained income if they increased work hours to cover costs or gain health insurance coverage. In our study, $22 \%$ of women gaining income reported insurance problems at 3 months. The SEER study found that $7 \%$ of women increased work hours to cover cancer-related medical expenses [39]. Interestingly, the group of women changing income levels, be it lost or gained, tended to have lower incomes. This may highlight that poorer women experience more volatility around cancer treatment, and more research looking at the reasons for these observations is needed.

\section{Study limitations}

First, the relatively small number of women whose incomes changed limited the power of the analysis and the number of covariates we could adjust for. We performed a propensity score adjusted analysis adjusting for additional covariates and obtained similar results. Second, we only had categorical income information which limited our ability to track all income changes. We were unable to look at changes for women maintaining $\geq \$ 100$, 000 , so our results may not be generalizable to those women. Also, our main outcome was change in household income over 12 months, but we did not collect information about the partner's employment or any longer term impacts. A final limitation with the income measure was that the information on household income was self-reported by participants and women may have interpreted what should be included in the measure of household income differently. For example, young women in college may or may not choose to report income and support from her parents in her understanding of her own household income.

Third, we were unable to adjust for potentially important confounders including social support and insurance status in the regression models of stress, anxiety and depression's impact on change in household income. If we had this information, we would expect the results from these regression models to be lower in magnitude than what we saw, due to the inverse relationship between these variables and psychosocial measures as well as income change. Fourth, because the trial occurred from 2012 to 2014, the financial crisis in 2008 and the Affordable Care Act in 2010 may have impacted the insurance and income stability of participants. Fifth, all information was self-reported, so there could be misclassification of income and psychosocial measures. Nonetheless, we believe that any misclassification was likely nondifferential. Lastly, women who participated in this trial may be different from the larger population of young breast cancer patients. While this is a national sample recruited from both community and academic sites, women in this study may be more health conscious, and have better financial or personal resources.

\section{Conclusions}

Stress, anxiety and depression were not associated with changes in household income in this study. However, young women with breast cancer with lower household incomes had a higher risk of losing household income than women with higher household incomes. This group of women may need more support during treatment and early survivorship from healthcare providers. Further research to understand the mechanism of income loss for young women with breast cancer, as well as research to understand interventions to support women at risk of losing income will be important to improving the care of young women with breast cancer. Additionally, research to understand the broader burden of financial toxicity for young women with breast cancer will help providers understand which patients could benefit from more support.

\section{Supplementary information}

Supplementary information accompanies this paper at https://doi.org/10. 1186/s12889-020-09562-z.

\footnotetext{
Additional file 1: eTable 1: Analysis by randomization arm (YWI vs PAI). eTable 2: Comparison of women included to women excluded. eTable 3: Amount of change in household income by income at baseline. eTable 4: Comparison of multinomial logistic regression model to the propensity score adjusted logistic regression model for the impact of stress, depression, and anxiety at baseline on changing household income vs maintaining same household income $<\$ 100,000$.
}

\section{Abbreviations \\ ADA: Americans with disabilities act; CARES-SF: Cancer rehabilitation evaluation system. short form; CES-D: Center for epidemiologic studies depression scale; Cl: Confidence interval; FMLA: Family and medical leave act; HADS: Hospital anxiety and depression scale; PAl: Physical activity intervention; PSS: Perceived stress scale; QOL: Quality of life; RR: Risk ratio; SEER: Surveillance, epidemiology, and end results; YWI: Young women's intervention}

\section{Acknowledgements}

We thank the participants of the focus groups, key informant interviews, pilot study, and the randomized controlled trial, and the 54 provider sites who enrolled patients. We thank Jane Kim for her input on this analysis. 


\section{Authors' contributions}

Conception and Design: EEC, SMR, KJR, WTB, MG, JL, KSH, MDH, RMT, KME, AHP. Provision of study materials or patients: KJR, MG, KSH, KME, AHP. Collection and assembly of data: SMR, KJR, WTB, MG, KSH, AHP. Data analysis and interpretation: EEC, SMR, KIR, WTB, MG, JL, KSH, MDH, RMT, KME, AHP. Manuscript writing, editing, and final approval of the manuscript: EEC, SMR, KIR, WTB, MG, JL, KSH, MDH, RMT, KME, AHP. All authors read and approved the final version of the manuscript.

\section{Funding}

This work was supported by an ASCO Improving Cancer Care grant (PI: Partridge), Susan G. Komen (PI: Partridge), NIH 5 K05 CA124415-05 (PI: Emmons) and the NIH training grants R25 CA98566-10, T32 CA009001-40, and T32 ES007069, and none of the funders had a role in the design of the study, the collection, analysis, and interpretation of data and in writing the manuscript.

\section{Availability of data and materials}

The datasets generated during and/or analyzed during the current study are available from the corresponding author on reasonable request.

\section{Ethics approval and consent to participate}

All procedures performed in studies involving human participants were in accordance with the ethical standards of the Dana-Farber Cancer Institute Institutional Review Board, which oversaw most of the study sites (some sites maintained their own institutional review) and with the 1964 Helsinki declaration and its later amendments or comparable ethical standards. Written informed consent was obtained from all participants prior to enrollment in the Young and Strong trial.

\section{Consent for publication}

Not applicable.

\section{Competing interests}

The authors do not have any conflicts of interest.

\begin{abstract}
Author details
${ }^{1}$ Harvard T.H. Chan School of Public Health, Boston, MA, USA. ${ }^{2}$ Current affiliation: Analysis Group, Inc., Boston, MA, USA. ${ }^{3}$ Medical Oncology, Dana-Farber Cancer Institute, 450 Brookline Avenue, Boston, MA 02215, USA. ${ }^{4}$ Harvard Medical School, Boston, MA, USA. ${ }^{5}$ Mayo Clinic, Rochester, MN, USA. ${ }^{6}$ Division of Biostatistics, Department of Data Sciences, Dana-Farber Cancer Institute, Boston, MA, USA. ”University of Rhode Island, Kingston, RI, USA.
\end{abstract}

Received: 11 November 2019 Accepted: 17 September 2020

Published online: 06 October 2020

\section{References}

1. American Cancer Society. Breast Cancer Facts \& Figures 2017-2018. Atlanta: American Cancer Society; 2017

2. Howlader N, Noone A, Krapcho M, Miller D, Bishop K, Kosary C, et al. SEER Cancer statistics review, 1975-2014. Bethesda, MD: National Cancer Institute; 2017.

3. Colleoni M, Anders CK. Debate: the biology of breast cancer in young women is unique. Oncologist. 2013;18(4):e13-5.

4. Howard-Anderson J, Ganz PA, Bower JE, Stanton AL. Quality of life, fertility concerns, and behavioral health outcomes in younger breast cancer survivors: a systematic review. J Natl Cancer Inst. 2012;104(5):386-405.

5. Tichy JR, Lim E, Anders CK. Breast cancer in adolescents and young adults: a review with a focus on biology. J Natl Compr Cancer Netw. 2013;11(9): 1060-9.

6. Partridge $\mathrm{AH}$. Cancer survivorship and the young breast cancer patient: addressing the important issues. Oncologist. 2013;18(8):e19-20.

7. Mahar KK, BrintzenhofeSzoc K, Shields JJ. The impact of changes in employment status on psychosocial well-being: a study of breast cancer survivors. J Psychosoc Oncol. 2008;26(3):1-17.

8. Bifulco G, De Rosa N, Tornesello ML, Piccoli R, Bertrando A, Lavitola G, et al. Quality of life, lifestyle behavior and employment experience: a comparison between young and midlife survivors of gynecology early stage cancers. Gynecologic Oncol. 2012;124(3):444-51.
9. Banegas MP, Guy GP Jr, de Moor JS, Ekwueme DU, Virgo KS, Kent EE, et al For working-age Cancer survivors, medical debt and bankruptcy create financial hardships. Health Aff (Millwood). 2016;35(1):54-61.

10. Veenstra CM, Wallner LP, Jagsi R, Abrahamse P, Griggs JJ, Bradley CJ, et al. Long-term economic and employment outcomes among Partners of Women with Early-Stage Breast Cancer. J Oncol Pract. 2017;13(11):e916-e26.

11. American Cancer Society. Health Insurance Laws. Available at: https://www. cancer.org/treatment/finding-and-paying-for-treatment/understandinghealth-insurance/health-insurance-laws.html. Accessed 4 May 2020.

12. Ruddy KJ, Greaney ML, Sprunck-Harrild K, Meyer ME, Emmons KM, Partridge $\mathrm{AH}$. Young women with breast Cancer: a focus group study of unmet needs. J Adolesc Young Adult Oncol. 2013;2(4):153-60.

13. Hewitt M, Breen N, Devesa S. Cancer prevalence and survivorship issues: analyses of the 1992 National Health Interview Survey. J Natl Cancer Inst. 1999:91(17):1480-6.

14. Jagsi R, Ward KC, Abrahamse PH, Wallner LP, Kurian AW, Hamilton AS, et al. Unmet need for clinician engagement regarding financial toxicity after diagnosis of breast cancer. Cancer. 2018;124(18):3668-76.

15. Ell K, Xie B, Wells A, Nedjat-Haiem F, Lee PJ, Vourlekis B. Economic stress among low-income women with cancer: effects on quality of life. Cancer. 2008;112(3):616-25.

16. Yabroff KR, Dowling EC, Guy GP Jr, Banegas MP, Davidoff A, Han X, et al. Financial hardship associated with Cancer in the United States: findings from a population-based sample of adult Cancer survivors. J Clin Oncol. 2016;34(3):259-67.

17. Tran G, Zafar SY. Financial toxicity and implications for cancer care in the era of molecular and immune therapies. Ann Transl Med. 2018;6(9):166.

18. Smith MW, Schnurr PP, Rosenheck RA. Employment outcomes and PTSD symptom severity. Ment Health Serv Res. 2005;7(2):89-101.

19. Zatzick D, Jurkovich GJ, Rivara FP, Wang J, Fan MY, Joesch J, et al. A national US study of posttraumatic stress disorder, depression, and work and functional outcomes after hospitalization for traumatic injury. Ann Surg. 2008;248(3):429-37.

20. Islam T, Dahlui M, Majid HA, Nahar AM, Mohd Taib NA, Su TT, et al. Factors associated with return to work of breast cancer survivors: a systematic review. BMC Public Health. 2014:14(Suppl 3):S8.

21. Nikbakhsh N, Moudi S, Abbasian S, Khafri S. Prevalence of depression and anxiety among cancer patients. Caspian J Intern Med. 2014;5(3):167-70.

22. Galway K, Black A, Cantwell M, Cardwell CR, Mills M, Donnelly M. Psychosocial interventions to improve quality of life and emotional wellbeing for recently diagnosed cancer patients. Cochrane Database Syst Rev. 2012;11:CD007064.

23. Macmillan Cancer Support and Opinion Leader Research. Worried sick: the emotional impact of cancer. 2006. https://www.macmillan.org.uk/documents/ getinvolved/campaigns/campaigns/impact_of_cancer_english.pdf.

24. Stevenson B, Wolfers J. Subjective well-being and income: is there any evidence of satiation? Am Econ Rev. 2013:103(3):598-604.

25. Kahneman D, Deaton A. High income improves evaluation of life but not emotional well-being. Proc Natl Acad Sci U S A. 2010;107(38):16489-93.

26. Aknin LB, Norton MI, Dunn EW. From wealth to well-being? Money matters, but less than people think. J Posit Psychol. 2009;4(6):523-7.

27. Greaney ML, Sprunck-Harrild K, Ruddy KJ, Ligibel J, Barry WT, Baker E, et al. Study protocol for Young \& Strong: a cluster randomized design to increase attention to unique issues faced by young women with newly diagnosed breast cancer. BMC Public Health. 2015;15:37.

28. Partridge AH, Ruddy KJ, Barry WT, Greaney ML, Ligibel JA, Sprunck-Harrild $\mathrm{KM}$, et al. A randomized study to improve care for young women with breast cancer at community and academic medical oncology practices in the United States: the young and strong study. Cancer. 2019;125(11):1799806.

29. Cohen S, Kamarck T, Mermelstein R. A global measure of perceived stress. J Health Soc Behav. 1983;24(4):385-96.

30. Zigmond AS, Snaith RP. The hospital anxiety and depression scale. Acta Psychiatr Scand. 1983:67(6):361-70.

31. Herrmann C. International experiences with the hospital anxiety and depression scale--a review of validation data and clinical results. J Psychosom Res. 1997:42(1):17-41.

32. Radloff LS. The CES-D scale: a self-report depression scale for research in the general population. Appl Psychol Meas. 1977;1(3):385-401.

33. Stafford L, Judd F, Gibson P, Komiti A, Quinn M, Mann GB. Comparison of the hospital anxiety and depression scale and the center for 
epidemiological studies depression scale for detecting depression in women with breast or gynecologic cancer. Gen Hosp Psychiatry. 2014;36(1): 74-80.

34. Coscarelli A, Heinrich RL. CARES-SF CAncer Rehabilitation Evaluation System Short Form. Cares Consultants, 1988. Accessed online 6/3/2019 at https:// cancer.ucla.edu/home/showdocument?id=723.

35. SAS 9.4. Cary: SAS Institute, Inc. https://www.sas.com/en_us/legal/editorialguidelines.html.

36. StataCorp. Stata statistical software: release 14. College Station: StataCorp LP; 2015.

37. Fenn KM, Evans SB, McCorkle R, DiGiovanna MP, Pusztai L, Sanft T, et al. Impact of financial burden of cancer on survivors' quality of life. J Oncol Pract. 2014;10(5):332-8.

38. Stone DS, Ganz PA, Pavlish C, Robbins WA. Young adult cancer survivors and work: a systematic review. J Cancer Surviv. 2017:11(6):765-81.

39. Jagsi R, Pottow JA, Griffith KA, Bradley C, Hamilton AS, Graff J, et al. Longterm financial burden of breast cancer: experiences of a diverse cohort of survivors identified through population-based registries. I Clin Oncol. 2014; 32(12):1269-76.

40. Bradley CJ, Yabroff KR, Dahman B, Feuer EJ, Mariotto A, Brown ML. Productivity costs of cancer mortality in the United States: 2000-2020. J Natl Cancer Inst. 2008:100(24):1763-70

41. Tolbert E, Bowie J, Snyder C, Bantug E, Smith K. A qualitative exploration of the experiences, needs, and roles of caregivers during and after cancer treatment: "That's what I say. I'm a relative survivor". J Cancer Surviv. 2018; 12(1):134-44.

42. Lambert SD, Girgis A, Lecathelinais C, Stacey F. Walking a mile in their shoes: anxiety and depression among partners and caregivers of cancer survivors at 6 and 12 months post-diagnosis. Support Care Cancer. 2013; 21(1):75-85.

43. Grunfeld E, Coyle D, Whelan T, Clinch J, Reyno L, Earle CC, et al. Family caregiver burden: results of a longitudinal study of breast cancer patients and their principal caregivers. CMAJ. 2004;170(12):1795-801.

\section{Publisher's Note}

Springer Nature remains neutral with regard to jurisdictional claims in published maps and institutional affiliations.

Ready to submit your research? Choose BMC and benefit from:

- fast, convenient online submission

- thorough peer review by experienced researchers in your field

- rapid publication on acceptance

- support for research data, including large and complex data types

- gold Open Access which fosters wider collaboration and increased citations

- maximum visibility for your research: over $100 \mathrm{M}$ website views per year

At $\mathrm{BMC}$, research is always in progress.

Learn more biomedcentral.com/submissions 